\title{
SCIENTIFIC RESEARCH AND DEVELOPMENT
}

\section{EFFECT OF SURFACTANTS ON REFRACTORY MATERIAL PROPERTIES ${ }^{1}$}

\author{
I. D. Kashcheev, ${ }^{2}$ K. G. Zemlyanoi, ${ }^{2}$ I. V. Kormina, ${ }^{3}$ and S. V. Markova ${ }^{3}$
}

Translated from Novye Ogneupory, No. 9, pp. 30 - 36, September, 2012.

Original article submitted April 1, 2012.

Results are provided for a study of the effect of Termoplast series plastifiers on structure formation for specimens based on chamotte and fired bauxite under laboratory and industrial conditions. A favorable effect is demonstrated for test additions both on compaction during pressing, and also on object strength properties after firing. With introduction of Termoplast T3 into commercial mixes in an amount of $0.5 \%$ total object porosity is reduced from $256-30$ to $10-15 \%$, and ultimate strength in compression increases from $30-35$ to $40-50 \mathrm{MPa}$.

Keywords: surface-active substance (SAS), Termoplast series plastifiers, refractory materials, porosity, compaction pressure.

Surface-active substances (SAS) have been used for a long time in refractory technology, promoting improvement of manufacturing technical and economic indices [1]. The weight fraction of SAS is normally within the limits $0.02-0.20 \%$ individually for each material and grinding conditions. Action of SAS is based on absorption reduction of strength, established for the first time by P. A. Rebinder, as a result of a reduction in solid specific surface energy. SAS are used most extensively in grinding solids. A very important question is the effect of SAS on structure formation both in freely poured powders, and also for compacted materials (pressed, briquetted, etc.).

The laying density for materials both with free pouring and under action of external pressure depends not so much on substance material particles as on their size, shape, surface condition, and structure. With a reduction in powder particle size the forces of adhesion arising with merging of particles increases sharply compared with their weight (gravitational force).Therefore particles of small sizes easily form loosely coagulated structures, i.e., disordered networks, hindering uniform distribution of particles within a volume and dense packing.

1 From the proceedings of the International Conference of Refractory Workers and Metallurgists (29 - 30 March, 2012, Moscow).

2 FGAOU VPO Ural Federal University, Ekaterinburg, Russia.

${ }^{3}$ OOO Poliplast Novomoskovsk, Novomoskovsk, Tula Region, Russia.
Even weak van der Waals forces of adhesion are sufficient in order to provide such strength for loose arched formations, hindering compaction. A layer of SAS or water, migrating over a surface (both outer and inner) creates two-dimensional pressure, which at the boundaries of an absorbed layer becomes higher than the strength of point contacts, as a result of which a system is converted into a dense condition.

It is well known that the total pressure $P_{\text {tot }}$ required for obtaining a specific apparent density during compaction of raw material $[2,3]$, is accumulated from pressure $P_{1}$ for compaction of a mix to a prescribed object density with uniform pressure distribution and with absence of frictional loss for particles over walls of a die: pressure $P_{2}$ for friction of a mix over die walls; pressure $P_{3}$, caused by nonuniform action of pressure in individual areas in a pressed mix as a result of nonuniformity of its moisture content, nonuniformity of grain size composition, and also friction of mix grains with other, and different height charging a die. Consequently, $P_{\text {tot }}=P_{1},+P_{2}+P_{3}$. It is difficult to determine these values by calculation. The total pressure depends on mix composition, its grain size, moisture content, and also on shape and size of objects and is determined by experience.

Since plastifying additions promote a reduction in loss of pressure by internal friction between particles and by friction over die walls, by changing mix rheology, they reduce $P_{3}$, and consequently the total compaction pressure. It is well known that during compaction of semidry mixes up to $50 \%$ of its force is consumed in overcoming friction forces. As a 
consequence, overpressing of raw material (pressing scrap) is unavoidable [4]. It should be noted that useful power of press equipment is reduced, and its wear increases. A reduction in pressure $P_{3}$ during compaction promotes an increase in press equipment productivity and a reduction in wear.

It has been shown in [5] that introduction of SAS into a charge of refractory material due to more dense packing of particles in the stage of mixing promotes an increase in its bulk density and leads to an increase in specimen strength in compression and a reduction in open porosity. Laboratory and industrial results are presented in this work for a study of the effect of SAS on the structure of compacted aluminosilicate objects. Specimens were formed with a different compaction pressure using 0.3 wt. $\%$ plastifier Termoplast T4. With this aim specimens were formed at a pressure of 80 , $105,130,15$, and $180 \mathrm{MPa}$ and then heat treated at $1450^{\circ} \mathrm{C}$. Results of determining specimen properties are provided in Table 1, and their microstructure is shown in Fig. 1.

Petrographic study of specimens (see Table 1) showed that they have different coloring (see Fig. 1), the higher compaction pressure, the darker is specimen color, and this is directly connected with their structure.

Specimens molded at a pressure of $80 \mathrm{MPa}$ (see Fig. $1 a, b)$ have a loose structure. Grains are uniformly distributed with a matrix. The matrix has insignificant mechanical strength; grains fall out during polishing. The total matrix porosity is estimated at more than $60 \%$. Specimens formed with a pressure of $105 \mathrm{MPa}$ (see Fig. 1c, $d$ ) have a denser structure, but between filler grains and matrix there are individual separation cracks, the matrix itself is uneven, and its surface is rough. There are point contacts between filler grains and matrix. Overall matrix porosity in a test specimen is on average $35-40 \%$. Specimens formed with a pressure of $130 \mathrm{MPa}$ (see Fig. 1e, $\mathrm{f}$ ) have a denser structure than the previous specimens. Grains of filler are uniformly distributed with the specimens volume; $50 \%$ of the matrix has an overall porosity of $35-40 \%$, and the other $50 \%$ of the matrix has an overall porosity of $25 \%$. A specimen has an uneven surface, grains are densely packed to the matrix, their strength is high; $30-40 \%$ of grains have separation cracks over the edge of grains. A specimen formed at a pressure of $155 \mathrm{MPa}$ (see Fig. $1 g, h$ ) has a dense structure and is distinguished qualitatively from the specimens considered before; $80 \%$ of filler grains on firing aggregate densely with the matrix, and separation cracks are found in $20 \%$ of the surface of grains. The matrix has a structure of fired chamotte, and clay is entirely reacted with ground chamotte. As a result of firing the matrix has coarse mullite growths. Overall matrix porosity is $15-20 \%$. For a specimen formed at $180 \mathrm{MPa}$ (see Fig. $1 i, j$ ) is identical to a specimen formed at a pressure of $155 \mathrm{MPa}$. An increase in compaction pressure led to compaction of the matrix structure. Matrix porosity is $10-15 \%$. Specimens formed at a pressure of more than $130 \mathrm{MPa}$ have an almost identical structure. The approximate total porosity of the ma-
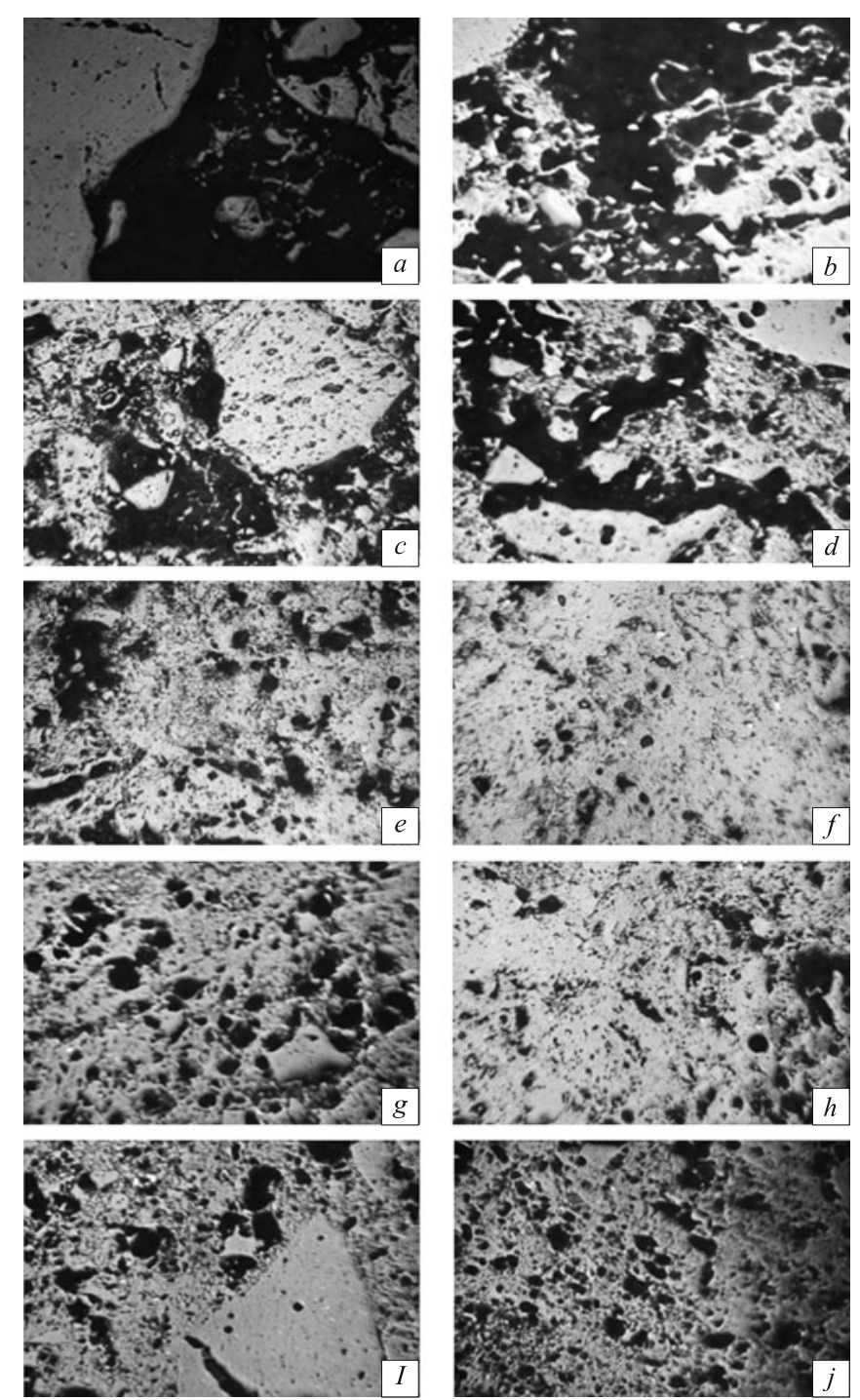

Fig. 1. Microstructure of chamotte specimens with addition of Termoplast T4 prepared with compaction pressure $80(a, b), 105(c$, $d), 130(e, f), 155(g, h)$, and $180 \mathrm{MPa}(i, j)$. Grain contact with matrix $(a, c, e, g, i)$ and specimen matrix $(b, d, f, h, j) . \times 80$.

trix off chamotte specimens formed at different compaction pressures is provided below:

Compaction

pressure, $\mathrm{MPa}$

Overall matrix

porosity, $\%$. 80 105 13 155 180

Thus, an increase in compaction pressure from 130 to $180 \mathrm{MPa}$ promotes some compaction of chamotte specimens; overall porosity of a matrix decreases to $10-15 \%$. Structural elements of objects (filler grains and matrix, and also synthesis products) are uniformly and densely abut each other, forming a dense carcass, exhibiting high strength. The degree of compaction and area of contact of phases increases uniformly with an increase in compaction pressure. 
TABLE 1. Chamotte Mix Composition and Specimens Prepared with Different Compaction Pressure Using 0.3 wt.\% Termoplast T4 Plastifier

\begin{tabular}{lccccc}
\hline \multicolumn{1}{c}{ Properties } & \multicolumn{3}{c}{ Property value with compaction pressure, MPa } \\
\cline { 2 - 6 } & 80 & 105 & 130 & 155 \\
\hline Raw material density, g/cm ${ }^{3}$ & 1.99 & 2.05 & 2.10 & 2.14 & 2.15 \\
Specimen properties after heat treatment at $1450^{\circ} \mathrm{C}: \Pi / \rho / \sigma(1.16)^{*}$ & $28 / 1.90 / 14$ & $27 / 1.93 / 15$ & $22 / 1.99 / 22$ & $21 / 2.01 / 34$ & $20 / 2.03 / 38$ \\
\hline
\end{tabular}

$* \Pi$ is open porosity, $\% ; \rho$ is apparent density, $\mathrm{g} / \mathrm{cm}^{3} ; \sigma$ is ultimate strength in compression, MPa. Bulk weight, $\mathrm{g} / \mathrm{cm}^{3}$, is given in brackets.
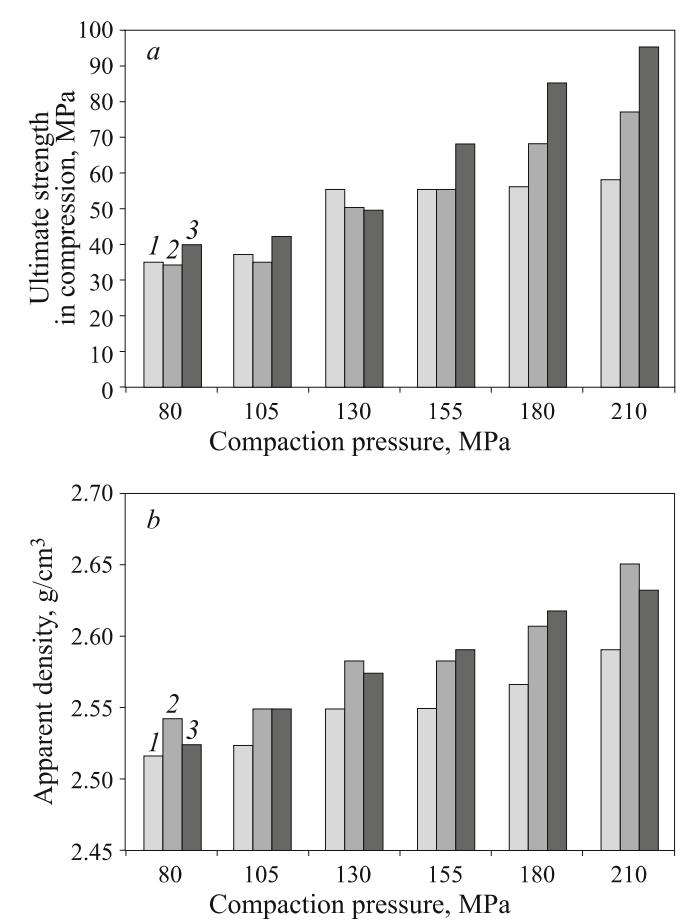

Fig. 2. Ultimate strength in compression $(a)$ and apparent density (b) of specimens prepared with different compaction pressure after heat treatment at $\left.1550^{\circ} \mathrm{C}: 1\right)$ specimens without addition; 2$)$ specimens with addition of $0.5 \%$ Termoplast $\mathrm{T} 5 ; 3$ ) specimens with addition of $0.3 \% \mathrm{ZMB}$.

Special tests were performed in studying the effect of SAS on high-alumina specimen properties prepared with different compaction pressure. Specimens based on bauxite without addition of SAS and with addition of plastifier Termplast T5 (in an amount of $0.5 \mathrm{wt} . \%$ ) and ZMB (in an amount of $0.3 \mathrm{wt} . \%$ ), were prepared with pressures of 80 , $105,130,155,180$, and $210 \mathrm{MPa}$. Then specimens were heat treated at $1550^{\circ} \mathrm{C}$. Results of determining properties are presented in Fig. 2 and Table 2, and microstructure is shown in Figs. 3 and 4.

It may be seen from Fig. 2 that for specimens without SAS addition (Fig. 2, column 1 ) maximum compaction and structural strength is achieved with a compaction pressure of $155 \mathrm{MPa}$; a further increase does not lead to marked improvement property quality indices. For specimens with ad- dition of SAS (Fig. 2, column 3 ) the best quality indices are achieved with compaction pressure of $130 \mathrm{MPa}$; an increase in it worsens properties.

Petrographic study of specimens showed that they have uniform coloring (see Figs. 3, 4), and the higher compaction pressure, specimen color is darker, and this is connected with their structure. The microstructure of high-alumina specimens prepared without using SAS with a pressure above $130 \mathrm{MPa}$ is almost identical. Specimens prepared with a pressure of 80,105 , and $130 \mathrm{MPa}$ show low strength and matrix porosity of the order of $30-35 \%$.

Coarse filler grains have almost no concretions (sinter) with the matrix and fall out during polishing. There is no overall object carcass. An increase in compaction pressure to $180-210 \mathrm{MPa}$ leads to an increase in density of the structure of high-alumina specimens and formation of overpressing cracks. Filler grains are distributed uniformly throughout specimen volume. Matrix sintering occurs pointwise, apparently due to an increase in overall specimen porosity. Matrix porosity for specimen prepared with a pressure of $80-155 \mathrm{MPa}$ without addition is $30-35 \%$, and for those prepared with a pressure of $180-210 \mathrm{MPa}$ it is $20-30 \%$. Thus, specimen structure with an increase in compaction pressure more than $130 \mathrm{MPa}$ is almost unchanged.

Specimens prepared using SAS show a denser structure. A specimen formed at a pressure of $105 \mathrm{MPa}$ (see Fig. 3, II, $c, d$ ) has a dense matrix structure with overall porosity of $30-35 \%$. There are cracks around coarse grains, and grains with a size of less than $0.4 \mathrm{~mm}$ grow densely with finely ground fractions. Grains of finely ground fractions are seen within the matrix.

A specimen molded with a pressure of $130 \mathrm{MPa}$ (see Fig. 3, III, $c, d$ ) has a dense homogeneous structure, and the amount of cracks around filler grains is $40-50 \%$. Matrix porosity is of the order of $20 \%$. Grains of fractions finer than $1 \mathrm{~mm}$ sinter with finely ground matrix and form a monolithic concretion. There are fine shrinkage cracks through the matrix.

A specimen formed at a pressure of $155 \mathrm{MPa}$ (Fig. 4, IV, $c, d$ ) has a dense homogenous structure. Filler grains are distributed uniformly through the specimen volume. Individual grains of fractions $0.5-1.0 \mathrm{~mm}$ within the matrix are separated from finely ground component by microcracks. Finer filler grains grow with the matrix. Matrix porosity is $30-35 \%$. 

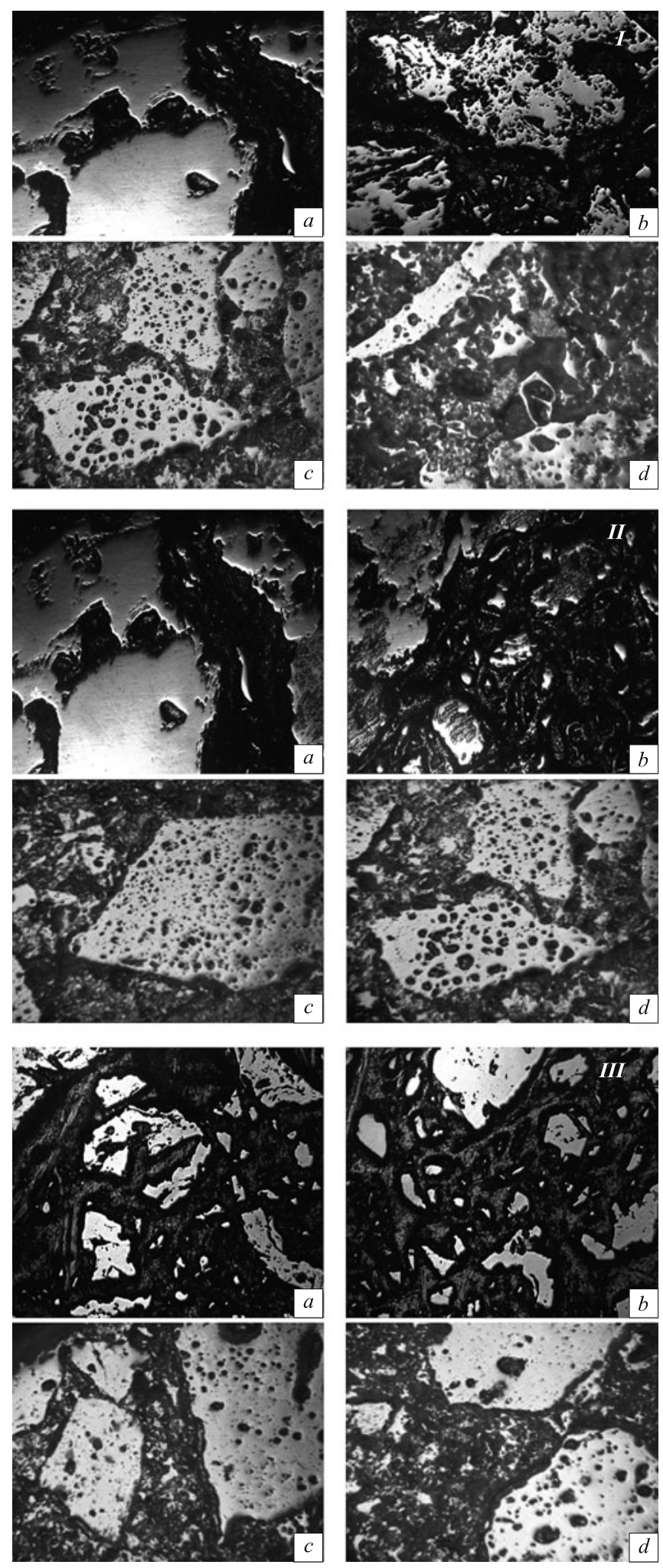

Fig. 3. Structure of specimens prepared with pressure $80(I), 105$ $(I I)$, and $130 \mathrm{MPa}(I I I)$ without addition $(a, b)$ and with addition of Termoplast T5 $(c, d)$. Grain contact with matrix $(a, c)$ and specimen matrix $(b, d) . \times 80$.

A specimen formed at a pressure of $180 \mathrm{MPa}$ (Fig. 4, $V, c, d)$ has a monolithic structure with uniform filler grain
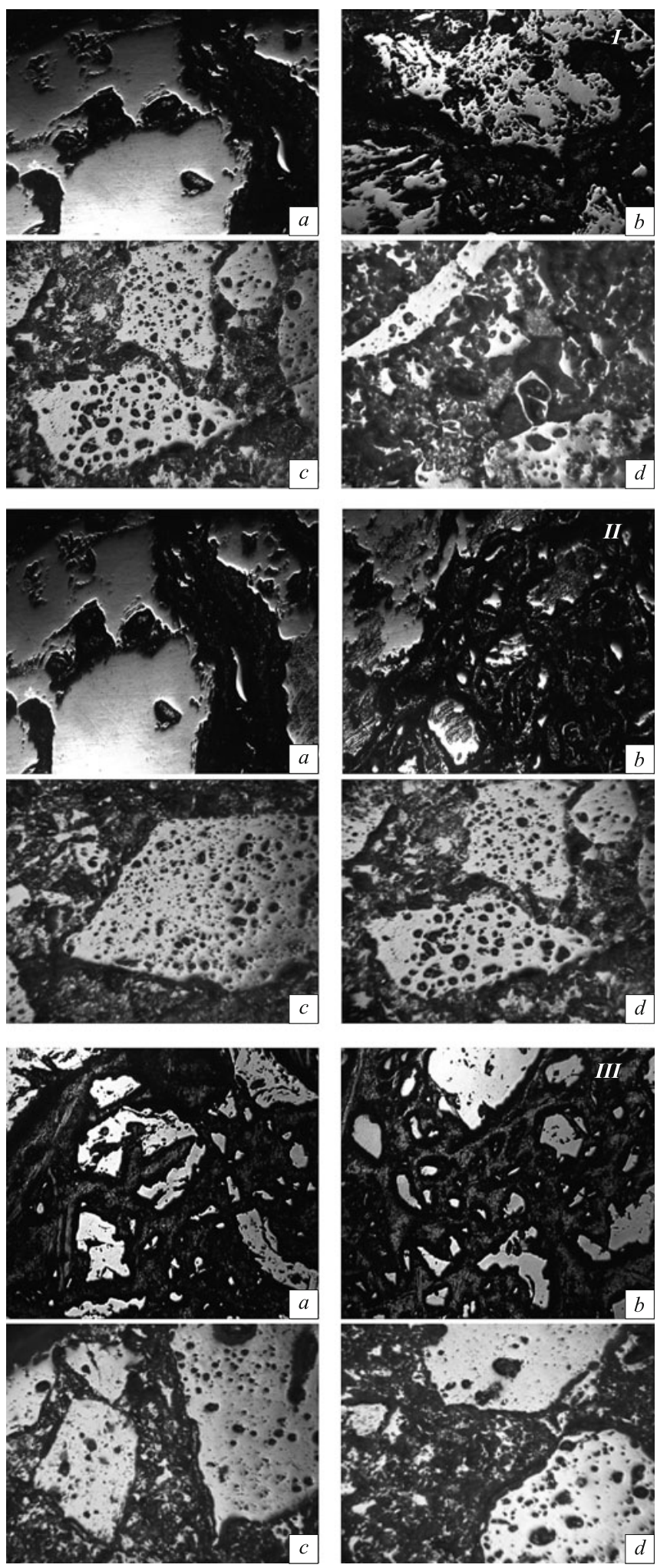

Fig. 4. Structure of specimens prepared with pressure 155 (IV), 180 $(V)$, and $210 \mathrm{MPa}(V I)$ without addition $(a, b)$ and with addition of Termoplast T5 $(c, d)$. Grain contact with matrix $(a, c)$ and specimen matrix $(b, d) . \times 80$.

distribution. Cracks around coarse grains are intermittent, and not continuous, as was observed in specimens consid- 
TABLE 2. Effect of Form of Plastifier on Properties of High-Alumina Mix and Specimens with Different Compaction Pressure

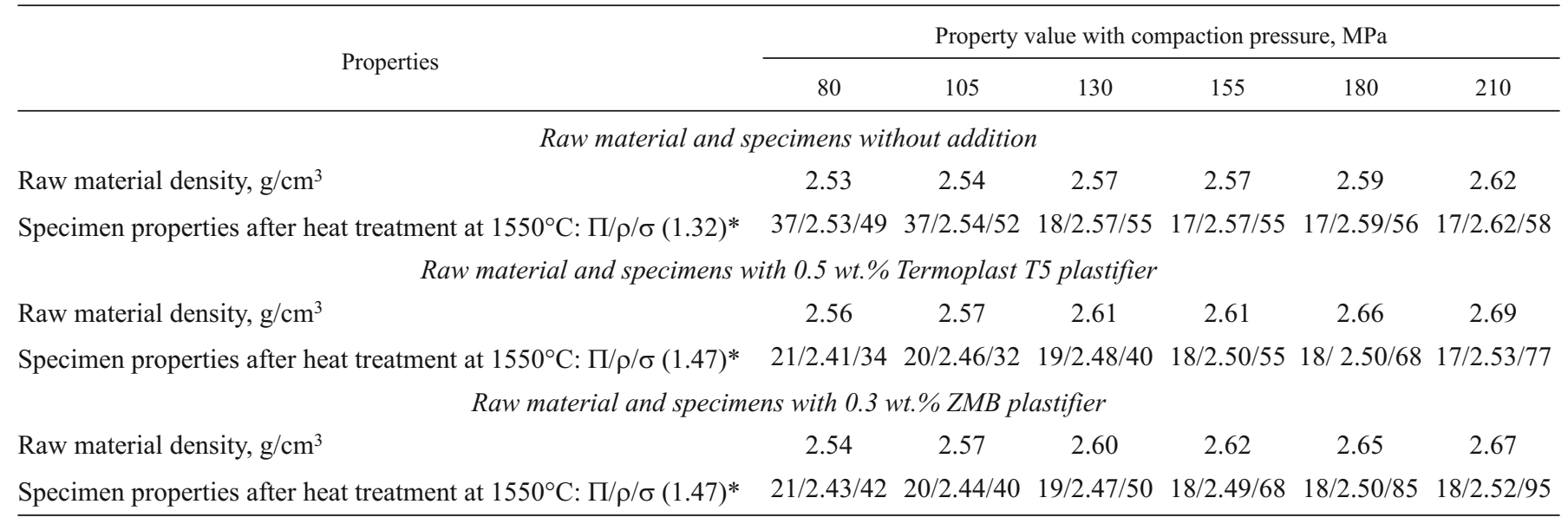

* Labelling same as in Table 1. Bulk density shown in brackets, $\mathrm{g} / \mathrm{cm}^{3}$

TABLE 3. Physicomechanical Properties of Industrial Objects

\begin{tabular}{|c|c|c|c|c|c|c|}
\hline Object grade & \multicolumn{2}{|c|}{ Raw material apparent density, $\mathrm{g} / \mathrm{cm}^{3}$} & \multicolumn{2}{|c|}{ Fired object open porosity, $\%$} & \multicolumn{2}{|c|}{ Ultimate strength in compression, $\mathrm{MPa}$} \\
\hline ShChU & $2.28-2.30$ & $2.30-2.32$ & $18-20$ & $16-17$ & $30-35$ & $40-50$ \\
\hline ShKN & $2.18-2.20$ & $2.23-2.25$ & $20-21$ & $18-20$ & $26-28$ & $30-31$ \\
\hline ShSP & $2.10-2.11$ & $2.12-2.14$ & $21-22$ & $19-20$ & - & - \\
\hline
\end{tabular}

ered previously. Filler grains during firing grow with finely ground fractions; matrix mullitization proceeds entirely. Matrix porosity is $10-15 \%$.

A specimen formed with a pressure of $210 \mathrm{MPa}$ (Fig. 4, $V I, c, d)$ has a monolithic structure and homogeneous distribution of filler grains within a matrix. Finely ground fractions finer than $1 \mathrm{~mm}$ during firing form a monolithic concretion with mullite-corundum; there are no cracks between filler and matrix. Matrix porosity is $7-10 \%$. Approximate overall porosity of a matrix of high-alumina specimens is provided below:

\begin{tabular}{|c|c|c|c|c|c|}
\hline $\begin{array}{l}\text { Compaction } \\
\text { pressure, } \mathrm{MPa} \text {. }\end{array}$ & 105 & 130 & 155 & 180 & 210 \\
\hline $\begin{array}{c}\text { Overall matrix } \\
\text { porosity, } \% \text {. }\end{array}$ & $30-35$ & 20 & $30-35$ & $10-15$ & $7-10$ \\
\hline
\end{tabular}

Specimens based on bauxite, prepared using SAS, in contrast to chamotte have higher structural density, caused by increased density of original materials of fired bauxite. Coarse grains of charge filler have good contact with fine fractions (matrix) of an object and a clearly defined relief. The degree of compaction of matrix refractory grains between each other increases with an increase in compaction pressure. With compaction pressure of $130 \mathrm{MPa}$ finely ground fraction $(<1 \mathrm{~mm})$ has a monolithic continuous contact as a result of sintering (see Fig. $3 c, d$ ). A further increase in compaction pressure to $210 \mathrm{MPa}$ promotes compaction of a structure, within which continuous cracks steadily decrease and they are less extensive, as a result of which grain contact with a matrix increases markedly and thereby there is a reduction in overall matrix porosity. The structure of specimens becomes monolithic (see Fig. 4, $V, c, d$ ).

Analysis of specimen properties and their microstructure shows that introduction of SAS and an increase in compaction pressure change not only material porosity, but also ultimate strength in compression for both chamotte specimens and for high-alumina specimens. With introduction of Termoplast T5 in an amount of $0.5 \%$ the ultimate strength in compression of high-alumina specimens, compacted at pressures of 80 and $210 \mathrm{MPa}$, after heat treatment at $1550^{\circ} \mathrm{C}$ increases from 34 to $77 \mathrm{MPa}$ respectively, and for specimens

TABLE 4. Actual Grain Size Composition of Industrial Objects According to Petrographic Analysis Data

\begin{tabular}{lccc}
\hline \multirow{2}{*}{ Object } & \multicolumn{3}{c}{ Fraction content, \%, mm } \\
\cline { 2 - 4 } & $3-1$ & $1-0.5$ & $<0.5$ \\
\hline Without addition & $30-35$ & $25-30$ & $35-45$ \\
With addition & $35-40$ & $30-35$ & $25-35$ \\
\hline
\end{tabular}



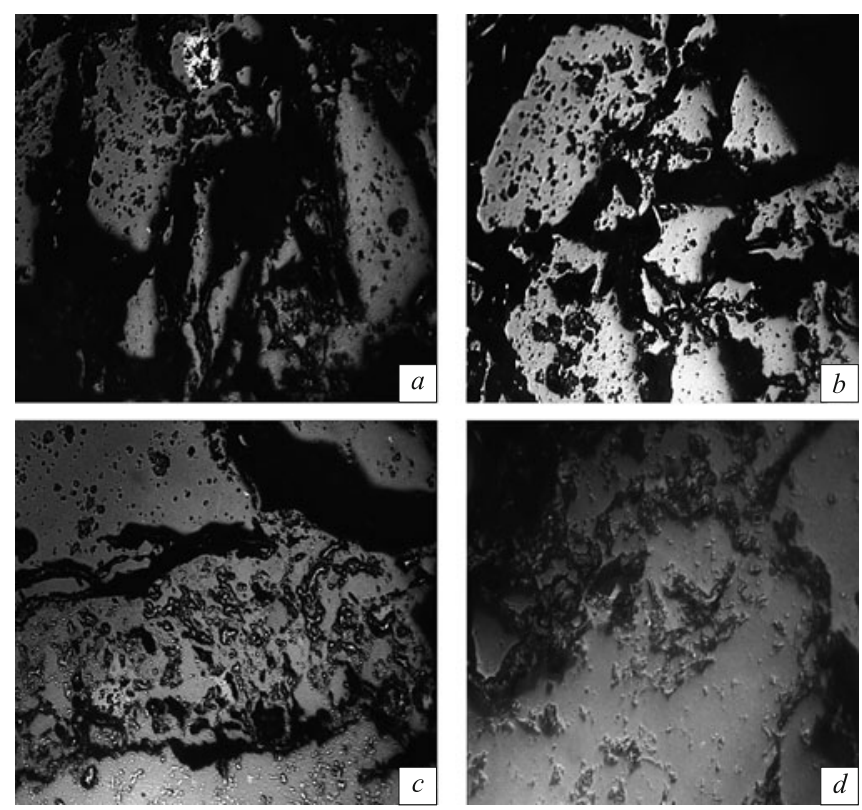

Fig. 5. Microstructure of chamotte objects grade $\mathrm{ShChU}$, prepared without SAS addition $(a, b)$ and with addition of Termoplast T3 $(c, d)$.

with addition of ZMB in an amount of $0.3 \%$ under similar conditions it increases from 42 to $95 \mathrm{MPa}$.

From the results of laboratory work SAS are recommended for industrial testing as plastifiers and temporary organic binders in production of aluminosilicate refractory objects. Testing was performed on standard chamotte objects of semidry compaction grades ShChu, ShKN, and ShSP. The starting materials used were lump chamotte ShKn, kaolin KO-3, and Druzhkovsk clay. Addition of Termoplast T3 was made to a charge in the mixing stage in an amount of $0.5 \mathrm{wt} . \%$. Objects were compacted in hydraulic presses type LAIS-1000 and SM-1085, and fired in a tunnel kiln with a maximum temperature of $1420^{\circ} \mathrm{C}$. Object properties after firing and with and without SAS addition are provided in Table 3 and shown in Fig. 5.

It may be seen from Table 3 that introduction of SAS made it possible to reduce open porosity by $2-3 \%$ and increase ultimate strength in compression for objects by $5-10 \mathrm{MPa}$. In the course of examination of industrial test batches a significant reduction was noted in the number of cracks and surface defects, and absence of chips over object edges and boundaries. In studying the structure of test specimens it was established that the matrix of specimens without addition has increased porosity, and this is caused by inadequate packing density during forming, and also low mechanical strength after firing, which in preparing microsections leads to grains falling out (Fig. $5 a, b$ ). Specimens with addition of Termoplast T3 (Fig. $5 c$, d) have a denser and stronger structure, which is due to:

- a change in mix rheology during manufacture (particle of fine fraction during mixing are attached to coarse grains and form agglomerates, and bulk density of this mix increases);

- a mix lays well in a die;

- there is partial relief of friction between mix and die, due to the addition, which moistens not only of grains, but also the die walls);

- more complete sintering due to an increase charge grain contact with fine fractions.

It has been established from results of petrographic study of specimens that:

1. Overall specimen porosity without addition is $25-30 \%$, and with SAS addition is $10-15 \%$.

2. The grain size composition of objects changes due to sintering of part of finely ground grains with coarse- and medium-size grains (Table 4).

About $90 \%$ of grains of fraction $3-1 \mathrm{~mm}$ in objects are isometric in shape, and this is specified by the quality of grinding equipment of the enterprise. Within specimens with addition of Termoplast T3 finely ground grains have dense growth filler grains. There are no cracks in objects with addition of SAS shown in Fig. $5 c, \mathrm{~d}$ in contrast to those in Fig. $5 a$, b between matrix and grains without SAS. Pores are both extended and round in shape, and are $50-65 \%$ closed.

In studying the structure of standard specimens pores that are caused by fall-out of finely ground filler grains, and also cracks, which encircle filler grains, are observed. The initial diameter of $80 \%$ of pores is from 10 to $15 \mu \mathrm{m}$.

\section{CONCLUSION}

The effect of plastifiers of the Termoplast series on structure formation for specimens based on chamotte and fired bauxite under laboratory and industrial conditions has been studied. A favorable effect is demonstrated for test additions both on compaction during pressing and also on strength properties of objects after firing. With introduction into an industrial mix of Termoplast $\mathrm{T} 3$ in an amount of $0.5 \%$ the overall porosity of objects is reduced from $25-30$ to $10-15 \%$, and ultimate strength in compression increases from $30-35$ to $40-50 \mathrm{MPa}$.

\section{REFERENCES}

1. K. K. Strelov, I. D. Kashcheev, and P. S. Mamykin, Refractory Technology [in Russian], Metallurgiya, Moscow (1988).

2. R. Ya. Popil'skii and F. V. Kondratov, Compaction of Ceramic Powders [in Russian], Metallurgiya, Moscow (1968).

3. R. Ya. Popil'skii and Yu. E. Pivinskii, Compaction of Powder Ceramic Mixes [in Russian], Metallurgiya, Moscow (1983).

4. E. M. Ved', E. M. Baklanov, E. F. Zharov, et al., Chemistry and Production of Structural Materials [in Russian], Budivel'nik, Kiev (1968).

5. I. D. Kashcheev, K. G. Zemlyanoi, I. V. Kormina, and S. V. Markova, "Effect of SAS on aluminosilicate refractory properties," Novye Ogneupory, No. 3, 139 - 146 (2011).9 